\title{
The impact of adverse environmental factors on the occurrence and prevalence of diseases in the Republic of Dagestan
}

\author{
Tamara F. Kosyreva ${ }^{1}$, Farida I. Astarkhanova ${ }^{1}$, Ibragim R. Astarkhanov', \\ Tamara S. Astarkhanova ${ }^{3}$, Leyla I. Alibalaeva ${ }^{4, *}$, and Ilyas N. Osmanov ${ }^{5}$ \\ ${ }^{1}$ Peoples' Friendship University of Russia, Department Pediatric dentistry and Orthodontics, 117198, \\ Moscow Miklukho-Maklaya str.6, Russian Federation \\ ${ }^{2}$ Dagestan State Agrarian University, Department of Ecology and Plant Protection, 367032, Republic \\ of Dagestan, Makhachkala, M. Gadzhieva str., 180, Russian Federation \\ ${ }^{3}$ Peoples' Friendship University of Russia, Faculty of agriculture and technology, 117198, Moscow \\ Miklukho-Maklaya str.6, Russian Federation a \\ ${ }^{3}$ Peoples' Friendship University of Russia, Department of Agrobiology, 117198, Moscow \\ Miklukho-Maklaya str.6, Russian Federation \\ ${ }^{4}$ Plekhanov Russian University of Economics, Department on Informatics, 117997, Moscow \\ Stremyanny lane, 36, Russian Federation \\ ${ }^{5}$ Dentol, 104469, Moscow Bratislavskaya str, 26, Russian Federation
}

\begin{abstract}
The article provides data on the environmental factors that play a role on the occurrence of various diseases and dentofacial anomalies. The data of epidemiological research in the region with adverse environmental factors are presented.
\end{abstract}

\section{The relevance of research}

The health of the population in modern globalization conditions is determined by the habitat and the content of harmful substances in the environment: in ambient air, drinking water, soil, and etc. In regards to this, the assessment of the factors determining the level of health and sanitary living conditions of the population in specific territories remains a research priority [1-5]. Recently, more attention has been paid to identification drinking water's impact on the health of the population, since the problem of supplying the population with good-quality drinking water in a number of regions of Russia has become a crisis [6-12]. The study of the influence of environmental factors on the prevalence of dental and maxillary anomalies, which occupy one of the leading positions in the dental morbidity structure of children and adolescents in various regions of the country is considerable scientific and practical interest, which is reflected in the studies of Russian and foreign scientists and indicates a tendency for their further growth [13-18]. Clarifying the causes of these abnormalities leads to the early detection of dentofacial anomalies and their prevention. In this connection, the priority research is the identification and

\footnotetext{
*Corresponding author: alibalaeva.li@rea.ru
} 
assessment of the role of individual factors determining the population's level of health and sanitary living conditions on specific territories. According to the initial determination, multifactorial pathology implies the obligatory participation of many factors of an endogenous and exogenous nature in the formation of the disease, while none of them separately being the cause of the development of the pathological process [19-22]. As a result of increased volumes of waste and pollutants of anthropogenic origin entering the atmosphere, soil, surface and groundwater, and from there, via trophic chains, reaching animals and humans, an increasing violation of the ecological balance of biogeocenoses has been observed in recent decades. High concentrations of heavy metals in the soil are dangerous; they lead to changes in the natural processes of migration and transformation of substances and the natural chemical composition of soils, plants and groundwater. Industrial waste (solid, liquid, gaseous) entering the natural environment is partially consumed by living organisms in the intake of water, air and food. It then actively moves through trophic networks and accumulates in animals and humans.

At the present stage, the ecological situation of water bodies is becoming more and more complicated, often taking forms of regional crises with an unfavorable forecast. In terms of water availability, The Republic of Dagestan is one of the leading regions in Russia. In Europe, there is 120-150 liters of water per day for one urban resident, in Moscow - 350, in our republic, taking into account the rural population -320 , in Makhachkala - 450 [2]. From one year to the next, we have an ever more acute problem of providing the population of the republic with high-quality drinking water. The population continues to consume potentially hazardous water, or to be more precise, 40 percent of the population drinks water that does not meet hygienic standards. Every fourth sample of water in the distribution network does not meet the requirements of the standards for sanitary-chemical parameters and every sixth sample does not meet the requirements of the standards for microbiological parameters [23]. In some cities and regions of Dagestan, water is characterized by a deficiency of its chemical composition [11, 12, 16, 18, 22].

Poor quality artesian water is the main cause of the high morbidity of the population in the northern regions of the country. Studying the prevalence of dentofacial anomalies and deformations depending on the quality of drinking water and the effectiveness of their treatment in areas of Republic where water consumption with a low fluorine content is observed is an urgent issue, since it would allow the population's demand for therapeutic and prophylactic orthodontics to be determined, the required volume of orthodontic care to be calculated, and the effectiveness of ongoing therapeutic and preventive measures to be judged on the basis of monitoring data. The prevalence of dentofacial anomalies and deformities in various regions of Russia according to researchers ranges from $30.9 \%$ to $76.5 \%[5,13,19]$. The data analysis indicates the absence of a downward trend in this pathology over the past years $[11,12,16]$. Moreover, morbidity has increased by 1.5 times in recent years.

The purpose of the study was to learn about the influence that poor-quality drinking water has on the prevalence of various diseases and dentofacial anomalies, and to figure out a set of measures to be taken and choose effective methods to reduce the adverse effects of groundwater in the artesian basin of the northern regions of the Republic of Dagestan.

\section{Study objectives:}

1. To study the prevalence of drinking water with low fluorine content, high arsenic content and an inadequate chemical composition, that contributes to the emergence of dentofacial anomalies and deformities in children aged 7, 12, and 17 years in the cities and regions of Dagestan.

2. To identify the correlation between the quality of drinking water and the prevalence of dentofacial anomalies in children living in the cities and regions of the Republic of Dagestan. 
3. To determine the content of carcinogenic substances (organic substances, heavy metals) in the drinking water of the studied area.

4. To identify the frequency of occurrence of various diseases and dental anomalies in children and adolescents in the studied areas of the republic.

Scientific novelty.

- The data on the chemical composition of the underground sources of drinking water supply in the northern regions of the Republic of Dagestan has been improved;

- The risk factors that determine the inadequacy of the drinking water in the city of Kizlyar and other areas of the northern regions of the Republic of Dagestan, due to the imbalance of the micro and macro-element composition have been revealed;

- The risks due to the influence of the quality of drinking water on the prevalence of dentofacial anomalies and deformities among school-aged children (7-17 years of age) have been identified.

- The frequency of the occurrence of caries in children consuming poor-quality drinking water with a high arsenic content and a low fluorine content has been revealed in the city of Kizlyar of the Republic of Dagestan.

\section{Material and research methods}

1. The surveying of children with DFA at the ages of 7-17 years to determine the children's level of health and the health of their mothers at the time of the children's birth. The data of the examination, signs of the disease, and biometric analysis data were recorded in the medical card in accordance to the clinical examination standards. the patient was diagnosed based the analysis of the obtained data.

2. 300 children in schools aged 7, 12, and 17 years old underwent research for this study (100 children from each age group) from 2016 to 2018 on the basis of the Dagestan State Agrarian University (Department of Ecology).

The main stages of the study. The studies were conducted in the period of 2016-2018 in the Kizlyar city and district, located in the northern region of the Republic of Dagestan. These territories are located in the zone of influence of the Terek-Kum artesian basin. Areas characterized by the same living conditions and diets are selected for research. The population's main source of drinking water is the underground artesian water of the Terek-Kum basin. The evaluation of the quality of drinking water was carried out according to the Federal Public Health Institution's "Center for Hygiene and Epidemiology in the Republic of Dagestan's" own research results and materials, as well as the research results and materials of the municipal budgetary institution "Housing and Communal Services Administration" of the urban district "Kizlyar City".

The risk criteria were: salt and microelement composition and microbiological indicators in drinking water; the content of pesticides, nitrates and microbiological indicators in food. The effect on health of regular consumption of water with a high arsenic content was calculated using the non-threshold effect of carcinogens [25].

The main research objects included water from underground water sources and drinking water from centralized water supply systems in urban and rural areas. In accordance with the objectives, the morbidity data was statistically analyzed. To compile a database, primary documentary sources on the incidence of DFA in the Republic of Dagestan in the period from 2016-2018 were used. This data was obtained at the Ministry of Health of the Republic of Dagestan and the Republican Dental Hospital. 


\section{Research results}

In the analysis of the personal data and clinical examination in accordance with the need for treatment criteria, we obtained the following data: for medical reasons, the need for each age group is quite high $(75 \%, 80 \%, 85 \%$ in age groups of 7,12 , and 17 years). In preventive measures, the need prevails among younger children $(70 \%, 35 \%, 20 \%$ for age groups of 7, 12, and 17 years), in medical procedures, the need among older children corresponds to $75 \%$, among children in the 12 -year-old age group, the need corresponds to $70 \%$. $40 \%$ of children 7-years-of-age are in need of treatment. The highest demand for treatment was among children from the Kizlyar and Tarumovsky districts, where the water is lower quality and contains high levels of arsenic, and low levels of fluorine. In second place are children from the Babayurt district and Kumtorkalinsky districts. The results of drinking water analysis correlate with our data.

\subsection{Water is one of the environmental risk factors in the occurrence of various diseases and dentofacial anomalies}

The total population of the district and city we are studying is only 73,354 people in the Kizlarsky district, and 48,907 people in the city as of 01/01/2018. In the Kizlyar district there are 22 municipalities and 484 settlements.

The population of the city of Kizlyar and other urban and rural settlements of the northern territories of the Republic of Dagestan is $100 \%$ provided with water by the centralized water supply which is based on the use of the groundwater of the Terek-Kum artesian basin. The volume of daily water consumption per person does not exceed 110 liters. An insufficient amount of water in the city has caused the introduction of a set schedule of water supply in the daytime, and at nighttime, the water supply stops altogether.

A significant contribution to inadequate water quality is made by an unsatisfactory water intake, which is characterized by an increased turbidity level of $3.1 \mathrm{mg} / \mathrm{l}(2.2 \mathrm{MPC})$, a fluorine deficiency $-0.18 \mathrm{mg} / \mathrm{l}(0.2 \mathrm{MPC})$, elevated concentrations of arsenic $-0.24 \mathrm{mg} / \mathrm{l}$ and is determined in single artesian wells from the second horizon (22 MPC) (Table 1, 2).

Table 1. Indicators of the quality of groundwater intake in the city of Kizlyar.

\begin{tabular}{|c|c|c|c|c|c|c|c|}
\hline \multirow{2}{*}{ Indicators } & \multicolumn{9}{|c|}{ Water intake } \\
\cline { 2 - 8 } & $\mathbf{1}$ & $\mathbf{2}$ & $\mathbf{3}$ & $\mathbf{4}$ & $\mathbf{5}$ & $\mathbf{6}$ & $\mathbf{7}$ \\
\hline Chromaticity, degrees & 0.15 & 0.05 & 0.15 & 0.1 & 0.2 & 0.2 & 0.2 \\
\hline Scent, score & 0.5 & 0.5 & 0.5 & 0.5 & 0.5 & 0.5 & 0.5 \\
\hline Turbidity, g/l & 2.82 & 2.53 & 1.75 & 3.1 & 1.86 & 0.66 & 0.66 \\
\hline Dry residue, mg/l & 0.58 & 0.67 & 0.54 & 0.57 & 0.67 & 0.67 & 0.63 \\
\hline Hardness mol/l & 0.46 & 0.5 & 0.52 & 0.37 & 0.5 & 0.37 & 0.35 \\
\hline Chlorides, mg/l & 0.44 & 0.93 & 0.86 & 0.82 & 0.79 & 0.95 & 0.90 \\
\hline Sulfates, mg/l & 0.39 & 0.44 & 0.56 & 0.54 & 0.53 & 0.5 & 0.38 \\
\hline Oxidation, CO2/l & 0.12 & 0.22 & 0.26 & 0.18 & 0.16 & 0.2 & 0.18 \\
\hline Ammonia, $\mathrm{mg} / \mathrm{l}$ & 0.4 & 0.26 & 0.2 & 0.33 & 0.33 & 0.06 & 0.06 \\
\hline Nitrates, $\mathrm{mg} / \mathrm{l}$ & 0.006 & 0.004 & 0.006 & 0.004 & 0.004 & 0.002 & 0.002 \\
\hline Nitrites, $\mathrm{mg} / \mathrm{l}$ & 0.002 & 0.002 & 0.003 & 0.002 & 0.005 & 0.001 & 0.003 \\
\hline Iron $\mathrm{mg} / \mathrm{l}$ & 3.0 & $1 \mathrm{D}$ & 3.0 & 1.33 & 1.1 & 0.8 & $1 \mathrm{D}$ \\
\hline Copper $\mathrm{mg} / \mathrm{l}$ & $\mathrm{n} / \mathrm{d}$ & 0.02 & 0.04 & 0.02 & 0.04 & 0.1 & $\mathrm{n} / \mathrm{d}$ \\
\hline Zinc, $\mathrm{mg} / \mathrm{l}$ & 0.012 & 0.008 & 0.012 & 0.01 & 0.006 & 0.008 & 0.002 \\
\hline Arsenic, $\mathrm{mg} / \mathrm{l}$ & 1.7 & 1.7 & 1.7 & 1.7 & 1.7 & 1.7 & 1.7 \\
\hline Fluorine, $\mathrm{mg} / \mathrm{l}$ & 0.19 & 0.19 & 0.19 & 0.19 & 0.19 & 0.19 & 0.19 \\
\hline
\end{tabular}


Table 2. Indicators that determine the adversity of drinking water in the city of Kizlyar (in shares from the MPC).

\begin{tabular}{|c|c|c|c|c|c|}
\hline Water intake & Turbidity & Hardness & Iron & Fluorine & Arsenic \\
\hline 1 & 1.82 & 0.48 & 3.0 & 0.19 & 1.7 \\
\hline 2 & 1.53 & 0.54 & 1.1 & 0.18 & 1.2 \\
\hline 3 & 1.75 & 0.52 & 3.0 & 0.16 & 2.4 \\
\hline 4 & 3.1 & 0.37 & 1.33 & 0.21 & 1.0 \\
\hline 5 & 0.86 & 0.50 & 1.1 & 0.22 & 2.1 \\
\hline 6 & 0.66 & 0.37 & 0.8 & 0.20 & 0.2 \\
\hline 7 & 0.66 & 0.35 & 1.1 & 0.19 & 2.1 \\
\hline
\end{tabular}

According to laboratory data, water from artesian wells in the populated areas of the Kilyarsky District and adjacent areas of the Northern Territories of Dagestan is characterized by elevated concentrations of arsenic. Arsenic concentrations range from 0.001 to $0.24 \mathrm{mg} / \mathrm{l}$ (from 1.0 to $22 \mathrm{MAC}$ ). According to microbiological indicators, the number of non-standard drinking water samples reaches more than $20 \%$.

\subsection{Evaluation of the risk of diseases and dentofacial anomalies due to exposure to elevated concentrations of arsenic in drinking water}

With modern environmental management, the evaluation of anthropogenic risk makes it possible to determine the effects of exposure to various substances and hazards $[13,18,25]$.

In evaluating the risk of the influence of toxic substances entering the human body over a certain period of time, the concentration of the accepted US EPA (US Environmental Protection Agency) on the maximum Acceptable concentration of substances in products, air, and water is taken into account.

When polluted water is consumed, options are used with a short exposure period (one day, ten days) and a long period (from several months to 10 years) and long-lasting option of use throughout the duration of a lifespan. The risk assessment and the indicated options provide the information necessary for decisions and conclusions.

The evaluation of the results obtained and calculations related to the presence of arsenic compounds in drinking water suggests that there is a health risk of the population of the city of Kizlyar and characterize it as a highly dangerous effect. In this situation, the growth of carcinogenic diseases among the population is expected. Thus, the conducted studies allow us to conclude that regular consumption of drinking water in the city of Kizlyar with arsenic content represents a risk associated with a high degree of carcinogenic effects.

As a result of the analysis of the data on the health status of the population of Kizlyar, children under 17 years of age, the number of diseases due to neoplasms and the urogenital system increased from 1.3 to 2 times; diseases of the digestive system, endocrine system and congenital dental anomalies increased almost twice [26].

\subsection{Correlation between the content of elevated concentrations of arsenic and low concentrations of fluoride in drinking water with dentofacial anomalies and the morbidity of the population of Kizlyar}

The quality of tap water in the city of Kizlyar depends not only on the natural composition of the water sources, but also on the condition of the water supply facilities and networks. Drinking water in the water supply does not meet the hygienic requirements for chemical composition and organoleptic properties. Deviations were revealed by an increased concentration of turbidity (2.25 MPC) and iron (3.2 MPC), insufficient content of water hardness indicators ( $0.35 \mathrm{MPC})$, and also content of elevated concentrations of heavy metal 
salts that are hazardous to human health, having the property of accumulating in the body, and low concentrations of fluoride have the ability to cause dental caries Many residents of the Kizlyar district and the city of Kizlyar use water from artesian wells as drinking water and the determination of the water quality indicators of groundwater at the water intakes of the city of Kizlyar had relevance in the research conducted. Many researches of scientists established the protective role of hardness salts in relation to the toxic properties of arsenic: for water with a hardness of $0.5 \mathrm{mEq} / \mathrm{l}$, the subliminal concentration of arsenic is $0.01 \mathrm{mg} / \mathrm{l}$, the threshold value is $0.05 \mathrm{mg} / \mathrm{l}$; for water with a hardness of $7.0 \mathrm{mEq} / \mathrm{l}$, the concentration of arsenic is $0.1 \mathrm{mg} / \mathrm{l}$, the threshold is $0.5 \mathrm{mg} / \mathrm{l}$. A correlation analysis of indicators of chemical elements in the composition of drinking water (increased concentration of arsenic, low fluorine and the ecological state of health of the population obtained statistically significant coefficients for some diseases.).

A correlation has been established between the low levels of fluoride in drinking water and the morbidity of caries, which is $\mathrm{R}=0.801$. The correlation coefficients between the content of arsenic in drinking water and congenital dentofacial anomalies in children and adolescents is $\mathrm{R}=0.758-0.781$, neoplasm diseases $-\mathrm{R}=0.806-0.918$ ); urogenital system $(\mathrm{R}=0.712-0.788)$, blood and blood-forming organs $(\mathrm{R}=0.732-800)$.

\section{Findings}

1. Studies have established that the chemical composition of the groundwater of the Terek-Kum artesian basin in the northern territories of the Republic of Dagestan is unbalanced.

2. Underground water used for drinking purposes does not correspond to standard indicators and is characterized by a high content of the maximum acceptable concentrations of arsenic by 2 times and iron up to 3 times. Fluorine content is 0.2 times below the norm, hardness is 0.3 times below the norm.

3. The increased content of iron and turbidity in water determines the discrepancy in the quality of drinking water by its organoleptic properties. The increased content of iron and turbidity in water also determines fluorine deficiency, low values of hardness, and its physiological inadequacy. The evaluation of the chemical composition of drinking water showed the predominance of signs of harmful drinking water due to the high content of arsenic, the proportion of which is $80 \%$; drinking water is unsafe due to non-compliance with microbiological indicators. Exposure to elevated concentrations of arsenic contained in the drinking water that we studies suggests a confirmation that the carcinogenic risk of developing dentofacial anomalies and cancer among the population of Kizlyar.

4. In children under 14 years of age living in the city of Kizlyar, there is a tendency of an increase in the morbidity of dentofacial anomalies by 1.5 and 2 times, and among adults, more than 2 times in neoplasms and from 1.5 to 2 times in diseases of the endocrine system, the digestive organs and the urinary system.

5. The dependence between the development of dental caries of the children population and the lack of fluoride in drinking water has been established $(\mathrm{R}=0.801)$ and the correlation between congenital dentofacial anomalies $(\mathrm{R}=0.758-0.781)$, the morbidity of neoplasms $(\mathrm{R}=0.806-0.918)$, and the level of arsenic in drinking water in children under 14 years of age and adolescents $15-17$ years of age.

The paper was financially supported by the Ministry of Education and Science of the Russian Federation on the program to improve the competitiveness of RUDN University among the world's leading research and education centres in the 2016-2020. 


\section{References}

1. S. L. Avaliani, M. M. Andrianova, E. V. Pechennikova, O. V. Ponomareva, Environment. Health risk assessment (Moscow, Consultation Centre for risk assessment, 1997)

2. A. P. Avtsyn, A. A. Zhavoronkov, M. A. Rish, L. S. Strochkova, Human microelementoses (Moscow, Medicine, 1991)

3. D. S. Kozlov, Odontoms in children (Materials of the II All-Russian University Scientific and Practical Conference of Young Scientists and Students in Medicine, Tula, 80-84, 2003)

4. G. P. Zarubin, Y. V. Novikov, Modern methods of purification and disinfection of drinking water (Moscow, 1976)

5. D. O. Romanov, Prevalence, prevention and treatment of dental anomalies and deformities in children of the Krasnodar Territory (Dissert, $\mathrm{PhD}$ in Medicine, 2010)

6. T. S. Astarkhanova, Problems of Development of the Agroindustrial Complex of the Region 22, 2, 52-55 (2018)

7. T. S. Astarkhanova, L. B. Bagavdinova, Water pollution by arsenic in the Republic of Dagestan (Collection of the All-Russian Scientific and Practical Conference, Makhachkala, 197-200, 2013)

8. I. R. Astarkhanov, Principles of ranking the territory according to the degree of pollution and intensity of the ecological situation (Environmental problems of agriculture and the scientific and practical ways to solve them, Collection of scientific papers of the international scientific-practical conference, Makhachkala, 205-215, 2017)

9. N. P. Vashkulat, Hygienic consequences of the use of arsenic-containing pesticides in agriculture (Hygiene of populated areas: Proc. report Rep. scientific conf., Kiev, 17, 96-98, 1978)

10. V. P. Belousov, Effect of water factor on the incidence of the population (Regional problems of health protection of the population of the Central Black Soil Region, Materials scientific conference, Edited by Professors Potapov A. I. Belgorod, 117-119, 2000)

11. M. M. Kerimov, Protection of public health in terms of exposure to the unbalanced chemical composition of the waters of the Terka-Kuma artesian basin (Dissert, $\mathrm{PhD}$ in Medicine, 149, 2004)

12. S. M. Shamov, Bulletin of New Medical Technologies 13, 3, 82 (2012)

13. L. K. Gubina, The study of the prevalence of dentition anomalies and deformities among children of school age. Identifying the percentage of orthodontic treatment performed and evaluating its effectiveness (Abstracts for the IV scientific-practical conference with international participation "Actual issues of children's dentistry and prevention of dental diseases", SPb, 27-28, 2008)

14. Hygienic standards GN 2.1.5.1315-03 Maximum Acceptable Concentrations (MAC) of Chemicals in Water of Water Bodies of Household, Drinking, and Cultural and Domestic Water Use, Decree of the Ministry of Health of April 30, 78 (2003)

15. RD population health indicators in 2017 - Makhachkala, Publishing House Health Ministry of the RD (2017)

16. E. Y. Omarieva, I. S. Babayants, L. Y. Panina, M. M. Saifutdinov 4, 10-12 (1998) 
17. A. P. Karaseva, Arsenic-containing water (some features of arsenic hydrochemistry) (Tr. Inst. Center, scientific. researches Inst. of balneology and physiotherapy, 92-109, 1981)

18. E. Y. Omarieva, Hygienic safety of the environment and public health of the Republic of Dagestan (The dissertation of Dr. Honey Sciences, Moscow, 320, 2002)

19. A. I. Pronyayeva, Anastasia Igorevna. Effect of adverse environmental factors on the occurrence of systemic enamel hypoplasia of permanent teeth in children (Diss. Ph.D)

20. A. G. Gasangadzhieva, Ecological and geographical principles for predicting the incidence of malignant neoplasms of the population of the Republic of Dagestan (Dissert, PhD in Biology, 2010)

21. G. M. Abdurakhmanov, A. G. Gasangadzhieva, A. B. Ryabova, Ecological and epidemiological features of the incidence of malignant neoplasms of the population of the city of Makhachkala of the Republic of Dagestan (Makhachkala, ALEPH, 2009)

22. S. V. Averyanov, S. V. Chuikin, O. S. Chuykin, A. V. Zubareva, Actual Problems of the Humanities and Ntural Sciences 6, 57-61 (2015)

23. I. A. Agadzhanyan, V. P. Kulakov, T. D. Zangieva, O. A. Ataniyazova, Ecological factors and reproductive function (Arkhangelsk, Human ecology, 1994)

24. The main indicators of the medical care of the Republic of Dagestan for 2016-2018 - Makhachkala. Health Ministry of the RD

25. S. M. Novikov, G. G. Onishchenko, Y. A. Rakhmanin, Hygienic risk assessment of environmental factors in the development of diseases (2003)

26. Indicators of the activities of medical and preventive treatment facilities of the Southern Federal District in 2016-2018 